\title{
Health outcomes of a subsidised fruit and vegetable program for Aboriginal children in northern New South Wales
}

\section{Andrew P Black \\ MB BS(Hons), \\ PhD, FAFPHM \\ Visiting Fellow, School of Population Health, ${ }^{1}$ and \\ General Practitioner ${ }^{2}$ \\ Hassan Vally \\ BSc(Hons), PhD, MAppEpi Senior Lecturer \\ Peter S Morris \\ MB BS, PhD, FRACP \\ Paediatrician \\ Mark Daniel \\ BSc, MSc, PhD, \\ Head, School of Population Health, and Research Chair. \\ Social Epidemiology, \\ Social Epidemiology and \\ Evaluation Research Group \\ Adrian J Esterman \\ BSc(Hons), MSc, PhD, \\ Professor of Biostatistics, \\ School of Nursing \\ and Midwifery \\ Fiona E Smith \\ BSc, MNutrDiet, APD Dietitian \\ Kerin O'Dea $\mathrm{BSc}, \mathrm{PhD}$, \\ Professor, Population \\ Health and Nutrition, \\ School of \\ Population Health \\ 1 Division of Health Sciences, University of \\ South Australia \\ Adelaide, SA \\ 2 Bulgarr Ngaru Medical \\ Aboriginal Corporation, \\ Grafton, NSW. \\ 3 School of Public Health and Human Biosciences, \\ La Trobe University, \\ Melbourne, VIC \\ 4 Department of \\ Paediatrics, Royal \\ Darwin Hospital, \\ Darwin, NT.}

ablack@bulgarr.com.au

MJA 2013; 199: 46-50 doi: 10.5694/mjal3.10445 $\mathrm{n}$ high-income countries, lower socioeconomic status is associated with both higher prevalence of non-communicable diseases and less-healthy dietary intake. ${ }^{1}$ In this context, promoting healthier nutrition, particularly increasing the intake of fruits and vegetables, has become an important public health priority. $^{2}$ For those on low incomes, it has been argued that the cost of healthier foods is an important barrier to improving nutrition. ${ }^{3}$ Though not widely implemented in Australia, food subsidy programs are one strategy with the potential to improve socioeconomic inequalities in dietary intake.

In 2005, a rural Aboriginal community-controlled health service initiated a program for providing subsidised fruits and vegetables to improve nutrition among disadvantaged Aboriginal families. This program aimed to engage families in preventive health care in partnership with the health service while also addressing the barrier of the cost of healthier food choices.

Our previously published evaluation of this program demonstrated improvements in biomarkers of fruit and vegetable intake among children. ${ }^{4}$ We were also interested in whether there were short-term health benefits of this program, which may have been indicative of enhanced functioning of the immune system due to improved nutritional status. ${ }^{5}$

Here, we report on whether participation in this fruit and vegetable subsidy program in northern New South Wales was associated with short-term improvements in the health of children in participating families using a number of markers, including any changes in episodes of illness, episodes of common clinical conditions, prescription of antibiotics and the prevalence of anaemia and iron deficiency.

\section{Abstract}

Objective: To evaluate the impact of a fruit and vegetable subsidy program on short-term health outcomes of disadvantaged Aboriginal children.

Design, setting and participants: A before-and-after study involving clinical assessments, health record audits and blood testing of all children aged 0-17 years $(n=167)$ from 55 participating families at baseline and after 12 months at three Aboriginal community-controlled health services in New South Wales. All assessments were completed between December 2008 and September 2010.

Intervention: A weekly box of subsidised fruit and vegetables linked to preventive health services and nutrition promotion at an Aboriginal Medical Service.

Main outcome measures: Change in episodes of illness, health service and emergency department attendances, antibiotic prescriptions and anthropometry.

Results: There was a significant decrease in oral antibiotics prescribed ( -0.5 prescriptions/year; $95 \% \mathrm{Cl},-0.8$ to -0.2 ) during 12 months of participation in the program compared with the 12 months before the program. The proportion of children classified as overweight or obese at baseline was $28.3 \%(38 / 134)$ and the proportion in each weight category did not change $(P=0.721)$ after 12 months. A small but significant increase in mean haemoglobin level (3.1 g/L; $95 \% \mathrm{Cl}, 1.4-4.8 \mathrm{~g} / \mathrm{L}$ ) was shown, although the proportion with iron deficiency (baseline, 41\%; follow-up, 37\%; $P=0.440$ ) and anaemia (baseline, $8 \%$; follow-up, 5\%; $P=0.453$ ) did not change significantly.

Conclusion: This fruit and vegetable subsidy program was associated with improvements in some indicators of short-term health status among disadvantaged Aboriginal children. A controlled trial is warranted to investigate the sustainability and feasibility of healthy food subsidy programs in Australia.

\section{Methods}

\section{The fruit and vegetable subsidy program}

In 2005, the Bulgarr Ngaru Medical Aboriginal Corporation established a fruit and vegetable subsidy program for low-income Aboriginal families in the Clarence Valley, NSW. The program combined annual health assessments, including dental and hearing check-ups, with receiving a weekly box of subsidised fruits and vegetables. Participating families collected boxes of seasonal fruits and vegetables (worth $\$ 40$ if $1-4$ children, or $\$ 60$ if $\geqslant 5$ children) at local greengrocers, making a copayment of $\$ 5$. Complementary seasonal recipes and practical cooking and nutrition education sessions facilitated by dietitians were provided. This is an ongoing program in the Clarence Valley; however, our evaluation involved new families receiving weekly boxes of fruits and vegetables over 12 months with children having health assessments at baseline and after 12 months. The recruitment and baseline assessments were undertaken between December 2008 and September 2009, with follow-up assessments completed between December 2009 and September 2010.

Additional funding enabled the Galambila Aboriginal Health Service in Coffs Harbour and the Giingan Darrunday Marlaanggu Aboriginal Health Clinic at Bowraville in the Nambucca Valley to institute similar fruit and vegetable subsidy programs. These health services also participated in this evaluation study. The availability of and arrangements with greengrocers varied between the communities. In Coffs Harbour, families received vouchers from the health service, which they redeemed at the greengrocer by selecting their own fruits and vegetables. In the Nambucca Valley, the greengrocer was in a 
different town to the health service, so the health service staff collected and delivered the boxes of fruits and vegetables to families at their homes and collected the \$5 contribution from them.

\section{Participants}

The participants were low-income (ie, unemployed or receiving pensions) Aboriginal families with one or more children $\leqslant 17$ years of age who were regular patients at the respective health services. Many of the children had an identified nutrition risk (eg, underweight or overweight, chronic or recurrent infections) or presented frequently with episodes of illness to the health service. Parents or carers provided written informed consent and agreed to their children having annual health assessments, including research evaluation assessments. Potential participants were identified by staff using the criteria described above and were invited to join the program. At Bulgarr Ngaru, there was a waiting list of eligible families who wanted to participate, but numbers were limited by available funding.

\section{Data collection and analysis}

Retrospective health records audits were used to compare the 12 months before participation in the program with the initial 12 months during participation. These audits were only completed if records for the entire 24 months were available. Health records were reviewed from Aboriginal health services, local hospitals and any other nominated general practice. The number of visits to any health service for illness or preventive health activities, the number of episodes of common clinical conditions, the number of visits to hospital emergency departments and the number of antibiotic prescriptions were compared during each 12-month period.

In addition, each participant had a health assessment, based on the Medicare Benefits Schedule Indigenous Child Health Check, before participation and 12 months after joining the program. For all participants at each health assessment height and weight were measured and non-fasting venous blood samples were obtained to assess haemoglobin and iron status. Height was measured without shoes or thick socks using a Seca 214 portable stadiometer or S\&M Instrument Co wall-mounted stadiometer. The participant stood with the heels together and the heels, buttocks and upper part of the back touching the upright of the stadiometer. Children under 3 years who were unable to stand unaided were measured supine using a Seca 210 baby measuring mat on a firm surface. Weight and body fat were measured using a Tanita UM030 Body Fat Monitor wearing light clothing only, with empty pockets and shoes and socks removed. Body fat was measured only for children in the Clarence Valley $\geqslant 7$ years, as per the Tanita recommendations. Children $<2$ years who were unable to stand unaided were weighed on a Soehnle Professional Babyscale 7725. Body mass index (BMI) in $\mathrm{kg} / \mathrm{m}^{2}$ was calculated for children 2-17 years. Blood samples collected from participants in the Clarence Valley were analysed at the Grafton Base Hospital pathology laboratory. Haemoglobin was analysed on a Roche Diagnostics Sysmex XT2000i haematology analyser. Serum iron and serum ferritin were analysed on a Roche Diagnostics Cobas Integra 800 chemistry analyser. Blood samples collected in Coffs Harbour and the Nambucca Valley were analysed at Symbion Laverty Pathology, Coffs Harbour. Full blood counts were analysed on a Sysmex XT-2000i haematology analyser. Serum ferritin assays were performed on the Siemens ADVIA Centaur XP automated immunoassay system. Serum iron was measured on the Siemens ADVIA 2400 chemistry system.

\section{Statistical analysis}

The mean and 95\% confidence interval of changes in the number of health service visits, common clinical conditions and antibiotic use, anthropometric measurements and levels of haemoglobin, iron and ferritin were evaluated in IBM SPSS Statistics, version 19 using a paired sample $t$ test and a general linear model to adjust for sex, age and community. The mean changes in these outcomes were assessed overall and by community, owing to differences in program implementation in each community. The analysis was based on complete data with no imputation for missing values. Based on an international classification of BMI centiles for age, ${ }^{6}$ the proportions of children who were underweight, normal weight, overweight and obese before participation were compared with the proportions after participation using the StuartMaxwell test of marginal homogeneity. The proportions of children with low haemoglobin, ferritin and iron before and after participation were compared using the McNemar test.

\section{Ethics}

Ethics approval was obtained from the University of Melbourne Human Research Ethics Committee, University of South Australia Human Research Ethics Committee, the Aboriginal Health and Medical Research Council of NSW and the North Coast Area Health Service human research ethics committee. Community consent was obtained from the boards of the three participating health services. The results of each child's pathology results were discussed with parents or carers, and overall summary results were discussed in community focus groups in the Clarence Valley.

\section{Results}

The demographic characteristics of 174 children who participated in the fruit and vegetable program are presented in Box 1. Of these, 167 children had an initial health assessment including anthropometry completed at baseline.

Retrospective clinical audits were completed for 167 children whose families received at least one box of subsidised fruits and vegetables. Seven children did not have clinical audits: three whose families moved from the area, and four whose families were withdrawn from the program for non-compliance with initial assessments.

After 12 months, 143 children had follow-up health assessments. Of those who did not complete followup assessments, nine were from families who moved from the area, nine failed to attend appointments and 13 were from families who dropped out of the program. The median period between baseline and follow-up health assessments was 370 days 


\begin{tabular}{|c|c|c|c|c|}
\hline & All communities & Clarence & Coffs Harbour & Nambucca \\
\hline No. of families & 55 & 30 & 12 & 13 \\
\hline No. of children & 174 & 90 & 36 & 48 \\
\hline No. of boys & 82 & 46 & 18 & 18 \\
\hline Age in years, mean (SD) & $7.6(4.2)$ & $7.5(3.8)$ & $11.0(3.3)$ & $5.8(4.3)$ \\
\hline $\begin{array}{l}\text { Children with at least one } \\
\text { smoker in household* }\end{array}$ & $107 / 164$ & $62 / 90$ & $18 / 36$ & $27 / 38$ \\
\hline $\begin{array}{l}\text { Families receiving } \\
\text { unemployment benefits, } \\
\text { pensions, no./total }\end{array}$ & $51 / 55$ & $28 / 30$ & $10 / 12$ & $13 / 13$ \\
\hline
\end{tabular}

2 Retrospective clinical audit data for health outcomes among participants for the 12 months before and 12 months after starting the subsidised fruit and vegetable program $(n=167)^{*}$

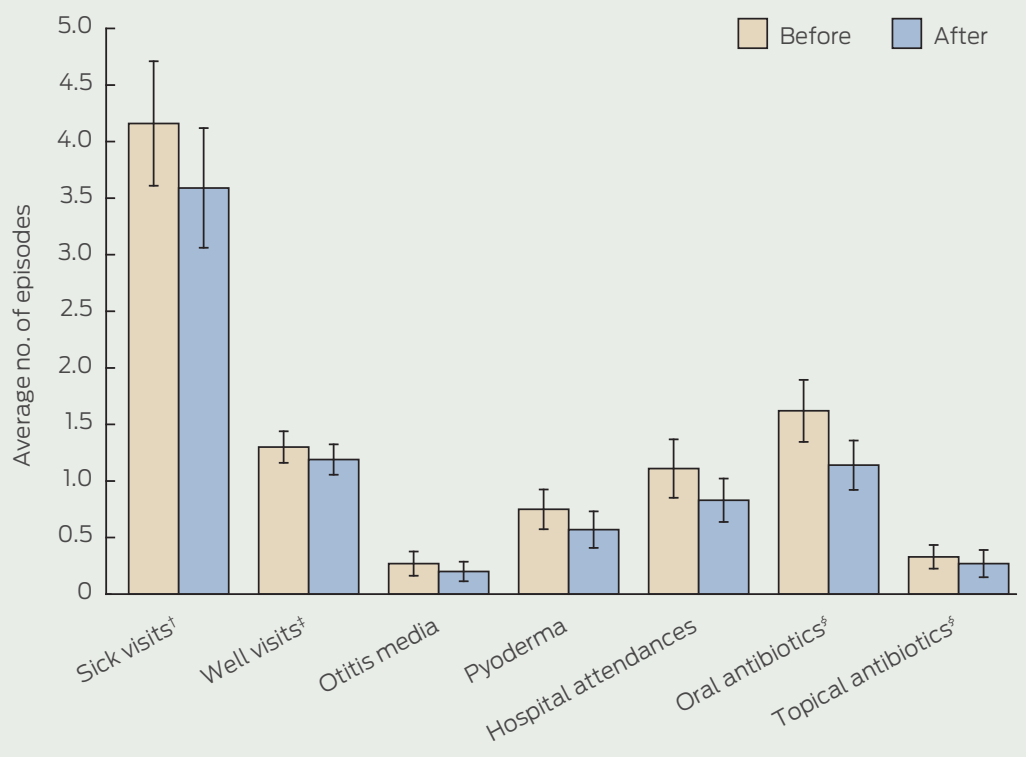

* Error bars show $95 \% \mathrm{Cl}$. $†$ Illness-related visits to health services. $\ddagger$ Preventive health-related visits to health services. $\$$ Number of prescriptions.

(interquartile range, 354-407 days). In the Clarence and Nambucca Valleys combined, 30 of 43 families collected $75 \%$ or more of the fruit and vegetable boxes available to them over the 12 months. These data were not available for Coffs Harbour.

\section{Anthropometric changes}

At the initial assessment of 134 children aged 2-17 years, $4.5 \%$ (6) were underweight, $67.2 \%$ (90) were normal weight, $14.9 \%$ (20) were overweight and $13.4 \%$ (18) were obese. Of 125 children aged 2-17 years who were reassessed after 12 months, $4.0 \%$ (5) were underweight, $66.4 \%$ (83) were normal weight, $16.8 \%$ (21) were overweight and $12.8 \%$ (16) were obese. There were no significant differences
0.017, $P=0.001$, respectively) (Box 2). There was also a non-significant reduction in episodes of pyoderma during program participation $(P=$ 0.093). After adjustment for sex, age and community, only the reductions in illness-related health service or hospital visits and in prescribing of oral antibiotics remained statistically significant (Box 3). An additional adjustment of change scores for the baseline values in the covariateadjusted models yielded no differences in the conclusions drawn other than a loss of statistical significance for the observed reduction in illnessrelated visits $(-0.5 ; 95 \% \mathrm{CI},-1.0$ to 0.03).

\section{Changes in haemoglobin and iron status}

A small, non-significant increase of $1.5 \mathrm{~g} / \mathrm{L}(P=0.076)$ in the mean haemoglobin level was shown; this effect increased in magnitude to $3.1 \mathrm{~g} / \mathrm{L}$ and was statistically significant after adjustment for community, sex and age (Box 4). An additional analysis adjusting for baseline haemoglobin level did not change this conclusion. Comparing the individual communities, a large, statistically significant increase in mean haemoglobin levelwas shown at Bowraville (7.8 g/L) but not in Coffs Harbour or the Clarence Valley $(P<0.001$ for difference between communities). The proportion of participants with anaemia decreased by $3 \%$ compared with baseline (Box 4). Iron deficiency, based on serum ferritin, was common at baseline $(41 \%)$. There were small decreases in the proportion of fruit and vegetable program participants with low ferritin and iron levels; however, there were no significant differences in mean serum ferritin and serum iron levels after the fruit and vegetable program compared with baseline with or without adjustment for community, sex and age (Box 4). Additional adjustment for baseline iron and ferritin levels did not change these findings.

The unadjusted data from clinical audits for the overall sample showed that during program participation the mean annual numbers of visits to any health service for illness, hospital emergency department attendances and oral antibiotic prescriptions were significantly lower $(P=0.037, P=$

\section{Discussion}

Aboriginal children from the NSW north coast who participated in this fruit and vegetable subsidy program had significantly fewer oral antibiotic 


\begin{tabular}{|c|c|c|c|c|c|c|c|}
\hline & $\begin{array}{l}\text { Sick } \\
\text { visits* }\end{array}$ & $\begin{array}{l}\text { Well } \\
\text { visits }^{\dagger}\end{array}$ & $\begin{array}{l}\text { Otitis media } \\
\text { episodes }\end{array}$ & $\begin{array}{l}\text { Pyoderma } \\
\text { episodes }\end{array}$ & $\begin{array}{l}\text { Hospital } \\
\text { attendances }\end{array}$ & $\begin{array}{c}\text { Oral } \\
\text { antibiotics }^{\ddagger}\end{array}$ & $\begin{array}{c}\text { Topical } \\
\text { antibiotics }^{\ddagger}\end{array}$ \\
\hline $\begin{array}{l}\text { Unadjusted mean } \Delta \text {-score } \\
(95 \% \mathrm{Cl})\end{array}$ & $\begin{array}{c}-0.6 \\
(-1.1 \text { to }-0.04) * *\end{array}$ & $\begin{array}{c}-0.1 \\
(-0.3 \text { to } 0.03)\end{array}$ & $\begin{array}{c}-0.1 \\
(-0.2 \text { to } 0.06)\end{array}$ & $\begin{array}{c}-0.2 \\
(-0.4 \text { to } 0.03)\end{array}$ & $\begin{array}{c}-0.3 \\
(-0.5 \text { to }-0.05)\end{array}$ & $\begin{array}{c}-0.5 \\
(-0.8 \text { to }-0.2) * *\end{array}$ & $\begin{array}{c}-0.06 \\
(-0.2 \text { to } 0.1)\end{array}$ \\
\hline $\begin{array}{l}\text { Adjusted }{ }^{\natural} \text { mean } \Delta \text {-score } \\
(95 \% \mathrm{Cl})\end{array}$ & $\begin{array}{c}-0.6 \\
(-1.2 \text { to }-0.001)^{* *}\end{array}$ & $\begin{array}{c}-0.2 \\
(-0.3 \text { to }-0.01)\end{array}$ & $\begin{array}{c}-0.1 \\
(-0.2 \text { to } 0.06)\end{array}$ & $\begin{array}{c}-0.2 \\
(-0.4 \text { to } 0.05)\end{array}$ & $\begin{array}{l}-0.2 \\
(-0.4 \text { to } 0.1)\end{array}$ & $\begin{array}{c}-0.5 \\
(-0.8 \text { to }-0.2) * *\end{array}$ & $\begin{array}{c}-0.1 \\
(-0.2 \text { to } 0.1)\end{array}$ \\
\hline
\end{tabular}

prescriptions over 12 months compared with the preceding year. The proportion of overweight or obese children after participation in this program did not change. Although height, weight and BMI had all increased significantly at the 12month follow-up as expected in children, there was no change in the percentage body fat among a subgroup who had this assessed. The prevalence of iron deficiency at baseline was $41 \%$, with anaemia in $8 \%$. There was a small but statistically significant increase in the mean haemoglobin level and a reduction in the proportion of children with anaemia, but only a non-significant $4 \%$ decrease in iron deficiency.

Our study demonstrates the potential to undertake evaluation studies in an Aboriginal community-controlled health service, despite the inherent limitations in a busy community-oriented service organisation. It is also an example of an Aboriginal community-directed program, which are far more common than intervention research, although few are documented in academic literature.

The nutritional challenges in this group of disadvantaged Aboriginal children are consistent with those reported in a study of other towns in northern NSW. ${ }^{7}$ Low intakes of fruits and vegetables and high intakes of energy-dense, nutrient-poor foods were reported among both Aboriginal and Torres Strait Islander and non-
Indigenous children aged 9-13 years, with a particularly high intake of sodium, calories, fat, sugary drinks and white bread by Indigenous boys. ${ }^{7}$ Although the nature of the intervention in our study differed from other nutrition interventions in remote Aboriginal communities, such as the Looma Healthy Lifestyle Program ${ }^{8}$ in Western Australia and the Minjilang Health and Nutrition Project ${ }^{9}$ in the Northern Territory, a common feature of these successful programs was strong community engagement. This, together with ongoing relationships, underpins other current Aboriginal community research programs. ${ }^{10,11}$

Community support for our healthy food program was fostered by the $88 \%$ subsidy for fruits and vegetables. Lower subsidies of $10 \%-20 \%$ have been used in other recent healthy food research and modelling studies. ${ }^{12-14}$ The higher subsidy used in this program reflects the substantial challenges and barriers to healthy nutrition faced by disadvantaged Aboriginal and Torres Strait Islander families. However, it is consistent with the WIC program (Special Supplemental Food Program for Women, Infants, and Children) in the United States and the Healthy Start program in the United Kingdom, which provide free healthy foods to low-income pregnant women and young children. The WIC program, in particular, has been shown to improve the nutritional status of participating women and children and pregnancy outcomes. ${ }^{15-19}$ There are still questions about the cost-effectiveness of these healthy food subsidy programs and whether the impacts on nutritional status are sustained. ${ }^{15,20,21}$ Food subsidies remain topical in Australia, given increasing concerns about food insecurity ${ }^{22}$ and as a policy alternative to compulsory income management and cash entitlements for low-income families.

The before-and-after uncontrolled study design limits the strength of our data. Regression to the mean due to paired data and the normal reduction in rates of childhood illnesses in older children may have also contributed to the findings. ${ }^{23}$ Regression to the mean was accounted for through use of allcovariate adjusted models that included age, sex and community, in addition to the baseline value for each outcome analysed. It is also possible that other unrelated environmental factors contributed to the improvements in nutrition and health outcomes, such as local early childhood and school nutrition programs. ${ }^{24,25}$ In addition, the health record audits may be subject to incomplete ascertainment, due to the ability of patients to potentially access more than one primary health care service and the lack of linkage of hospital records across area health services. It is not possible to predict the impact of this on the findings; however, it is likely to have had a similar impact before and after participation.

4 Changes in haemoglobin and iron status among fruit and vegetable program participants $(n=129)$

\begin{tabular}{|c|c|c|c|c|c|c|c|}
\hline & \multicolumn{2}{|c|}{ Mean level (SD) } & \multicolumn{2}{|c|}{$\Delta$-score $(95 \% \mathrm{Cl})$} & \multicolumn{3}{|c|}{ Proportion classified as low } \\
\hline & Before & After & Unadjusted mean & Adjusted mean* & Before (no. [\%] $)^{\dagger}$ & After $(\text { no. }[\%])^{\dagger}$ & $P$ \\
\hline Haemoglobin $(\mathrm{g} / \mathrm{L})^{\ddagger}$ & $126.8(12.3)$ & $128.2(10.5)$ & $1.5(-0.2$ to 3.1$)$ & $3.1(1.4 \text { to } 4.8)^{* *}$ & $12 / 150(8 \%)$ & $7 / 137(5 \%)$ & 0.453 \\
\hline Ferritin $(\mu \mathrm{g} / \mathrm{L})^{\delta}$ & $33.3(24.2)$ & $35.2(22.5)$ & $3.2(-0.5$ to 6.2$)$ & $1.7(-2.5$ to 6.0$)$ & $63 / 152(41 \%)$ & $51 / 139(37 \%)$ & 0.440 \\
\hline $\operatorname{Iron}(\mu \mathrm{mol} / \mathrm{L})^{9}$ & $12.7(6.0)$ & $13.2(5.3)$ & $0.5(-0.6$ to 1.6$)$ & 0.8 ( -0.5 to 2.0$)$ & $43 / 152(28 \%)$ & $32 / 139(23 \%)$ & 0.405 \\
\hline
\end{tabular}

*Adjusted for sex, age and community. $\uparrow 129$ participants had valid haemoglobin, ferritin and iron at baseline and follow-up. Additional participants had valid pathology at either baseline or follow-up as shown. $¥$ Reference interval (RI): $\geqslant 5$ years, $115-140 \mathrm{~g} / \mathrm{L} ;<5 \mathrm{years,}, 105-140 \mathrm{~g} / \mathrm{L}$. $\$ \mathrm{RI}$ : boys, $20-200 \mu \mathrm{g} / \mathrm{L}$; girls, 29-200 $\mu \mathrm{g} / \mathrm{L}$. 9 RI, 11-28 $\mu \mathrm{mol} / \mathrm{L}$. ** Significantly different to zero $(P<0.05)$. 
We showed an association between subsidised fruits and vegetables and short-term health improvements in this study. We have previously reported increased plasma biomarkers of fruit and vegetable intake among participants, ${ }^{4}$ which supports the hypothesis that improvements in dietary intake contributed to improved health outcomes. A controlled study is needed for further confirmation of these findings and to allow investigation of the cost-effectiveness of such a program. Our findings are consistent with prospective studies demonstrating an association between healthy nutrition and improved long-term health outcomes. ${ }^{26,27}$

A larger trial is warranted to investigate the sustainability and feasibility of healthy food subsidy programs in Australia. The program could be adapted to target low-income families more generally. The design of future healthy food subsidy studies needs to allow us to distinguish between the relative contribution of fruit and vegetables and comprehensive primary health care to the improved outcomes. This program aimed to engage families in preventive health activities more fully than previously, which may also have contibuted to the observed health outcomes. This is relevant, given the cost of food subsidies and the need to target effective interventions. Food subsidy programs in the US operate independently of health services, although the WIC program assists participants to access health and social services. ${ }^{28}$

This fruit and vegetable subsidy program was associated with improvements in some indicators of short-term health status among disadvantaged Aboriginal children. These health outcomes and the associated improvements in biomarkers of fruit and vegetable intake ${ }^{4}$ have the potential to reduce health disparities in the population.

Acknowledgements: We acknowledge the families who participated in this evaluation study and the staff at the three health services, particularly David Ferguson and May Robinson from the Bulgarr fruit and vegetable committee, for the success of the study. Kerry Hampshire, Nicole Turner, Karen Spark, Lea Clayden, Marie Gough and Irina Holmes, Tracy Bradshaw and the team at Giingan
Darrunday Marlaanggu Aboriginal Health Service contributed significantly to the clinical assessments. Thanks to Robyn Liddle for database design and Judy Boatswain for assistance with data entry. This study was supported by National Health and Medical Research Council, Australia (PhD scholarship 520681 and Program Grant 320860)

Competing interests: No relevant disclosures.

Received 8 Apr 2013, accepted 11 Jun 2013.

1 Marmot M, Friel S, Bell R, et al; Commission on Social Determinants of Health. Closing the gap in a generation: health equity through action on the social determinants of health. Lancet 2008; 372: 1661-1669.

2 World Health Organization. Fruit and vegetables for health. Report of a joint FAO/WHO workshop, 1-3 September 2004, Kobe, Japan. Geneva: World Health Organization and Food and Agriculture Organization, 2005. http://www.who.int/entity/ dietphysicalactivity/publications/fruit vegetables_report.pdf (accessed Jun 2013).

3 Drewnowski A, Darmon N. Food choices and diet costs: an economic analysis. J Nutr 2005; 135: 900-904.

4 Black AP, Vally H, Morris P, et al. Nutritional impacts of a fruit and vegetable subsidy programme for disadvantaged Australian Aborigi-nal children. Br J Nutr 2013; Jun 7: 1-9. [Epub ahead of print.]

5 Calder PC, Jackson AA. Undernutrition, infection and immune function. Nutr Res Rev 2000; 13: 3-29.

6 Cole TJ, Flegal KM, Nicholls D, Jackson AA. Body mass index cut offs to define thinness in children and adolescents: international survey. BMJ 2007; 335: 194.

7 Gwynn JD, Flood VM, D'Este CA, et al. Poor food and nutrient intake among Indigenous and nonIndigenous rural Australian children. BMC Pediatr 2012; 12: 12.

8 Rowley KG, Su Q, Cincotta M, et al. Improvements in circulating cholesterol, antioxidants, and homocysteine after dietary intervention in an Australian Aboriginal community. Am J Clin Nutr 2001; 74: 442-448.

9 Lee AJ, Bailey AP, Yarmirr D, et al. Survival tucker: improved diet and health indicators in an aboriginal community. Aust J Public Health 1994; 18: $277-285$

10 Kanyini Vascular Collaboration [website]. Sydney: The George Institute for Global Health; 2012. http://www.kvc.org.au (accessed Jul 2012).

11 Lehmann D, Arumugaswamy A, Elsbury D, et al. The Kalgoorlie Otitis Media Research Project: rationale, methods, population characteristics and ethical considerations. Paediatr Perinat Epidemiol 2008:22:60-71.

12 Ni Mhurchu C, Blakely T, Jiang Y, et al. Effects of price discounts and tailored nutrition education on supermarket purchases: a randomized controlled trial. Am J Clin Nutr 2010; 91: 736-747.

13 Ball K, McNaughton SA, Mhurchu CN, et al. Supermarket Healthy Eating for Life (SHELf): protocol of a randomised controlled trial promoting healthy food and beverage consumption through price reduction and skill-building strategies. BMC Public Health 2011; 11: 715

14 Vos T, Carter R, Barendregt J, et al; ACEPrevention Team. Assessing cost-effectiveness in prevention (ACE-Prevention): final report. Brisbane and Melbourne: University of Queensland and Deakin University, 2010. http://www.lowitja.org.au/assessing-cost- effectiveness-prevention-ace $\%$ E2\%80\% 93prevention-final-report (accessed Jun 2013).

15 Rush D, Leighton J, Sloan NL, et al. The National WIC Evaluation: evaluation of the Special Supplemental Food Program for Women, Infants, and Children. VI. Study of infants and children. Am J Clin Nutr 1988; 48 (2 Suppl): 484-511.

16 Rush D, Sloan NL, Leighton J, et al. The National WIC Evaluation: evaluation of the Special Supplemental Food Program for Women, Infants, and Children. V. Longitudinal study of pregnant women. Am J Clin Nutr 1988; 48 (2 Suppl): 439-483.

17 Rush D, Alvir JM, Kenny DA, et al. The National WIC Evaluation: evaluation of the Special Supplemental Food Program for Women, Infants, and Children. III. Historical study of pregnancy outcomes. Am J Clin Nutr 1988; 48 (2 Suppl): 412-428.

18 Metcoff J, Costiloe P, Crosby WM, et al. Effect of food supplementation (WIC) during pregnancy on birth weight. Am J Clin Nutr 1985; 41: 933-947.

19 Hoynes HW, Page ME, Stevens AH. Is a WIC start a better start? Evaluating WIC's impact on infant health using program introduction. NBER Working Paper No.15589. Cambridge, MA: National Bureau of Economic Research, 2009. http://www.nber.org/papers/w15589 (accessed Jun 2013).

20 D'Souza L, Renfrew M, McCormick F, et al. Foodsupport programmes for low-income and socially disadvantaged childbearing women in developed countries. Systematic review of the evidence. London: National Institute for Health and Clinical Excellence, 2006. http://www.nice.org.uk/ aboutnice/whoweare/aboutthehda/ hdapublications/p105.jsp (accessed Jun 2013)

21 Joyce T, Racine A, Yunzal-Butler C. Reassessing the WIC effect: evidence from the Pregnancy Nutrition Surveillance System. J Policy Anal Manage 2008; 27: 277-303.

22 Foley W, Ward P, Carter P, et al. An ecological analysis of factors associated with food insecurity in South Australia, 2002-7. Public Health Nutr 2010; 13: 215-221.

23 Barnett AG, van der Pols JC, Dobson AJ. Regression to the mean: what it is and how to deal with it. Int J Epidemiol 2005; 34: 215-220.

24 Healthy Kids Eat Well, Get Active. Live Life Well @ School. Sydney: NSW Department of Health, NSW Department of Education and Communities and the Heart Foundation, 2012. http://www.healthykids.nsw.gov.au/campaignsprograms/live-life-well-@-school.aspx (accessed Jul 2012)

25 Healthy Kids Eat Well, Get Active. About Munch \& Move. Sydney: NSW Department of Health, NSW Department of Education and Communities and the Heart Foundation, 2012. http://www. healthykids.nsw.gov.au/campaigns-programs/ about-munch-move.aspx (accessed Jul 2012).

26 Ford ES, Zhao G, Tsai J, Li C. Low-risk lifestyle behaviors and all-cause mortality: findings from the National Health and Nutrition Examination Survey III Mortality Study. Am J Public Health 2011; 101: 1922-1929.

27 Khaw KT, Wareham N, Bingham S, et al. Combined impact of health behaviours and mortality in men and women: the EPIC-Norfolk prospective population study. PLoS Med 2008; 5: el2.

28 United States Department of Agriculture Food and Nutrition Service. How the WIC helps. 2004. http://www.fns.usda.gov/wic/aboutwic/ howwichelps.htm (accessed Jun 2013). 